\title{
TELETRABAJO Y AMPLIFICACIÓN DE LA DESIGUALDAD EN LA SOCIEDAD POST-PANDEMIA ESPAÑOLA
}

\author{
Hugo Valenzuela-García \\ Universitat Autónoma de Barcelona
}

\section{RESUMEN}

Aunque el teletrabajo ya existía antes de la pandemia, su irrupción e implementación a gran escala sugiere un cambio de paradigma laboral. En general la recepción de esta modalidad laboral ha sido optimista pero su implantación repentina pone de manifiesto una serie de desigualdades estructurales a muy diferentes niveles: entre países miembros de la UE, entre zonas geográficas y sectores comerciales, entre grados de cualificación/ capacitación y en términos de edad, etnia y clase. Esta desigualdad estructural presenta complejos retos para la sociedad post-covid. El texto se basa en los datos extraídos de una encuesta administrada a 66 teletrabajadores durante el confinamiento; en datos comparativos recabados de informes oficiales, y en literatura teórica sobre la evolución del capitalismo cognitivo y la emergencia del trabajo remoto.

Palabras clave: Teletrabajo; Desigualdad; Covid-19; Capitalismo cognitivo; Clase creativa.

\begin{abstract}
Although teleworking existed before the pandemic, its emergence and large-scale implementation suggest a paradigm shift in the world of work. While the reception of teleworking has been optimistic in general, its sudden introduction reveals a series of underlying structural inequalities, between manual workers and cognitive workers, between European Union member countries, geographic territories, business sectors,
\end{abstract}


job qualification, age, ethnicity, and class. Such structural inequality, amplified by teleworking, presents significant challenges for work and society in the future of postCovid society. The text draws on data extracted from a survey administered to 66 teleworkers during lockdown; on comparative data collected from official reports, and the theoretical literature on the evolution of cognitive capitalism and the emergence of remote work.

Keywords: Telework; Inequality; Covid-19; Cognitive capitalism; Creative class.

\section{INTRODUCCIÓN ${ }^{1}$}

Según el Foro Económico Internacional, la desigualdad socioeconómica ya constituye el principal desafío mundial, por delante del calentamiento global, del acceso a agua potable o del auge de los nacionalismos (WEF, 2020). OXFAM estima que el 1\% más rico del mundo ya posee más del doble de la riqueza que 6.900 millones de personas (WEF, 2020).Tanto la brecha entre ricos y pobres, como el porcentaje de población en situación de exclusión, está en sus máximos históricos desde que se inició la serie en los años 70 (OECD, 2015 y 2016). Con el reciente encadenamiento de la crisis financiera de 2008 y la recesión que presagia la pandemia de la covid-19, podemos prever que esta escalada tienda al alza.

La pandemia ha hecho retroceder más de una década los tímidos indicadores de mejora económica de esta década (Gómez, 2020; Magallón, 2020a; Maqueda, 2020). La Organización Internacional del Trabajo (OIT) estima que la reducción mundial de horas trabajadas durante el segundo trimestre de 2020, en relación al último de 2019, equivale a la pérdida de 400 millones de empleos a tiempo completo (Doncel, 2020). Se prevé que la pandemia destruya 195 millones de puestos laborales en todo el mundo (OIT), poniendo en riesgo a más de 1.250 millones de personas empleadas y exponiendo, en particular, a millones de familias que dependen del sector informal (Magallón, 2000b). En Estados Unidos, en solo dos meses de pandemia, se acumularon 33 millones de desempleados y en Europa se saldó con la pérdida de 12 millones de puestos laborales. En el caso de España, en los primeros meses de confinamiento, los efectos directos en el mercado laboral afectaron a 4,3 millones de personas (Magallón, 2000b), entre parados, trabajadores sujetos a expedientes de regulación temporal de empleo (ERTE), autónomos

\footnotetext{
1. Este artículo se ha elaborado en el contexto del proyecto I+D+i Dimensión comunitaria, redes personales y exclusión social. Programa Estatal de I+D+i Orientada a los Retos de la Sociedad, del Plan Estatal de Investigación Científica y Técnica y de Innovación 2017-2020. PID2019-111251RB-I00 (2019- 2023). El autor es miembro de Egolab-GRAFO y de CREIS: Centro de Estudios y de Investigación en Emprendimiento e Innovación Social (https://espainnova.uab.cat/es/creis)
} 
y asalariados de baja (muchos de ellos a causa del virus). Hasta 2026 no se espera que España recupere los niveles de desempleo anteriores a esta crisis y, aunque se prevé que en 2021 se empiece a crear empleo, según el FMI solo se recuperará uno de cada cinco empleos perdidos este año: de los 965.000 empleos destruidos, solo se crearán 187.000 (Doncel, 2020).

Ante este desolador panorama, el teletrabajo ha sido la principal tabla de salvación al que se ha aferrado el $80 \%$ de las empresas españolas para salvar su capital y los puestos laborales (Medel Vicente, 2020). Pero esta decisión, sobrevenida por las circunstancias, se realizó en ausencia de planificación, medios (computadoras, teléfonos, software o a menudo conexión a internet de alta velocidad), infraestructura (espacio adecuado, mobiliario ergonómico, iluminación, etc.), formación (en TIC o en objetivos orientados a fines en lugar de a tareas, etc.) o experiencia (pues la mayoría de los trabajadores no estaba familiarizada con el trabajo remoto) (Aranda, 2020; García, 2020; Lafraya, 2020). Como colofón, aunque el artículo 13 del Estatuto de los Trabajadores señala que el teletrabajo debe ser fruto de un acuerdo voluntario entre empresa y empleado, este se impuso en ausencia de suficiente regulación (Puentes, 2020) y sin dar demasiadas opciones a los trabajadores: era trabajar desde casa, ERTE o despido.

La implantación extensiva del teletrabajo ha sido acogida con particular entusiasmo por un sector amplio de la población (fundamentalmente empresarios de grandes corporaciones, consultores, algunos trabajadores y muchos periodistas), dando rienda suelta a toda suerte de futuribles. Por ejemplo, muchos entusiastas consideran que esta nueva forma de desempeño laboral posibilitará la conciliación familiar definitiva; generará una sociedad más emancipada; provocará una revolución domótica en la que los hogares del futuro integrarán espacios de ocio, producción y tecnología de modo más saludable y sostenible; o contribuirá a que la economía sea más verde y respetuosa con el medioambiente.

Ese futuro ideal está por ver. La radiografía del teletrabajo en el actual contexto de pandemia refleja una preocupante amplificación de la desigualdad en términos de países, territorios, sectores, puestos laborales, salarios, edad y género.

En el presente artículo describiremos brevemente el contexto histórico y los orígenes socio-tecnológicos que hacen posible el empleo a distancia, ubicándolo en el marco de la expansión del capitalismo cognitivo. A continuación, expondremos los resultados hallados sobre una muestra de teletrabajadores en tiempos de pandemia y los compararemos con otras encuestas e informes oficiales. En la discusión de los resultados pondremos de manifiesto las desigualdades mencionadas. Las conclusiones incluirán una reflexión sobre la deriva socio-tecnológica de esta nueva forma de producción y sobre las nuevas desigualdades en la sociedad post-pandemia: una nueva era que no invita al optimismo. 


\section{TELETRABAJO Y CAPITALISMO COGNITIVO}

La expansión del trabajo remoto durantela pandemia no se entendería sin un doble proceso que surge a mediados del siglo pasado. Por una parte, la revolución de las tecnologías de la información y la comunicación (TIC), que sientan las bases infraestructurales para posibilitar el trabajo remoto. Por otra parte, el cambio de régimen de acumulación (Boyer, 1992) del fordismo al post-fordismo, que conlleva una progresiva substitución de bienes materiales producidos en masa por la creación estratégica de intangibles de gran valor añadido dirigidos a sectores específicos de la sociedad. En este apartado desarrollaremos de manera general estos dos aspectos.

Hasta el siglo XIX, la producción doméstica era la norma para la mayoría de comerciantes, agricultores y artesanos (herreros, carpinteros, tejedores, armeros). La Revolución Industrial cambió radicalmente este modelo, estableciendo una drástica separación entre el mundo industrial y la esfera del hogar. Los modelos de producción taylorista y fordista, basados en la producción en serie de mercancías de consumo masivo, concentró a los obreros en fábricas y los redujo, mediante rutinarios movimientos efectuados durante largas y agotadoras jornadas laborales, a meros engranajes de la máquina. Ni siquiera el incremento de los salarios y los incentivos laborales de posguerra lograron aminorar la alienación de estos trabajadores, desprovistos de vías para potenciar sus capacidades (Reygadas et al., 2012).

Pero a mediados de los años 60, el paradigma fordista-taylorista entra en crisis. Su excesiva rigidez en un mercado cambiante, la crisis del crudo y el surgimiento de una fuerte competencia comercial asiática lo hacen poco competitivo. Durante el postfordismo, el nuevo eje industrial del neoliberalismo, la economía de escala, basada en la producción masiva, dio lugar a una economía de alcance (scope economy), en la que la creación e innovación devienen recursos empresariales estratégicos. Esta transformación de la estrategia productiva comportó no solo un cambio de dimensión productiva, sino también una transformación radical de la naturaleza de la mercancía, de los espacios y tiempos de producción, de las cadenas de creación de valor, de la gestión y supervisión de la producción y hasta del propio obrero.

Con el post-fordismo, la creación del valor se expone a un proceso productivo radicalmente distinto al de la mercancía convencional. Con la búsqueda de productos rentables y exclusivos, destinados a sectores específicos de la sociedad, emerge también el capitalismo cognitivo, basado en la explotación de la propiedad intelectual de patentes, licencias, software y servicios (formación, educación, investigación, consultoría, etc.). En este nuevo escenario, la disciplina fabril no resulta solo inadecuada sino también contraproducente. En la nueva ideación de mercancías basadas en el conocimiento, el modelo de gestión tradicional, vertical y jerárquico propio de las fábricas, deja paso a formas más sutiles de extracción de la plusvalía y control del obrero (como 
la autodisciplina y el control por pares) debido a que el trabajo mismo adquiere una dimensión significativa sin precedentes en la historia (Overell, 2008).

A diferencia dela industria tradicional, en este contexto el espacio y el tiempo de producción se tornan no solo más flexibles y volubles, sino también más comprimidos, reduciendo drásticamente el tiempo entre la producción y el consumo, por una parte, y volatilizando las tradicionales dimensiones espacio-temporales de la producción, por la otra (Harvey, 1990). Puesto que la innovación tiene más posibilidades de darse en ambientes de trabajo amables, relajados, flexibles y comunicativos (Lloveras et al., 2009), la tendencia en las empresas del conocimiento es convertir las antiguas oficinas en espacios socializantes e híbridos que mezclan lo doméstico, lo lúdico y lo laboral, para hacer que los trabajadores se sientan como en casa y puedan de este modo expresar su subjetividad y destilar así conocimiento comercializable. Los espacios laborales proyectan la idiosincrasia del capitalismo cognitivo: se aplanan los organigramas y, con ello, se difumina la división de espacios; las estructuras se vuelven móviles y fluidas; se tintan de tonalidades, adornos, mobiliarios y complementos informales, divertidos e iconoclastas; los elementos de una esfera irrumpen en la otra (por ejemplo, se observa la presencia de juegos o instrumentos musicales en el trabajo y la ubicuidad de la tecnología móvil en el hogar); ocio y trabajo se funden en un continuo; y se entrelazan vocación y personalidad, construyendo de manera monolítica la identidad del individuo.

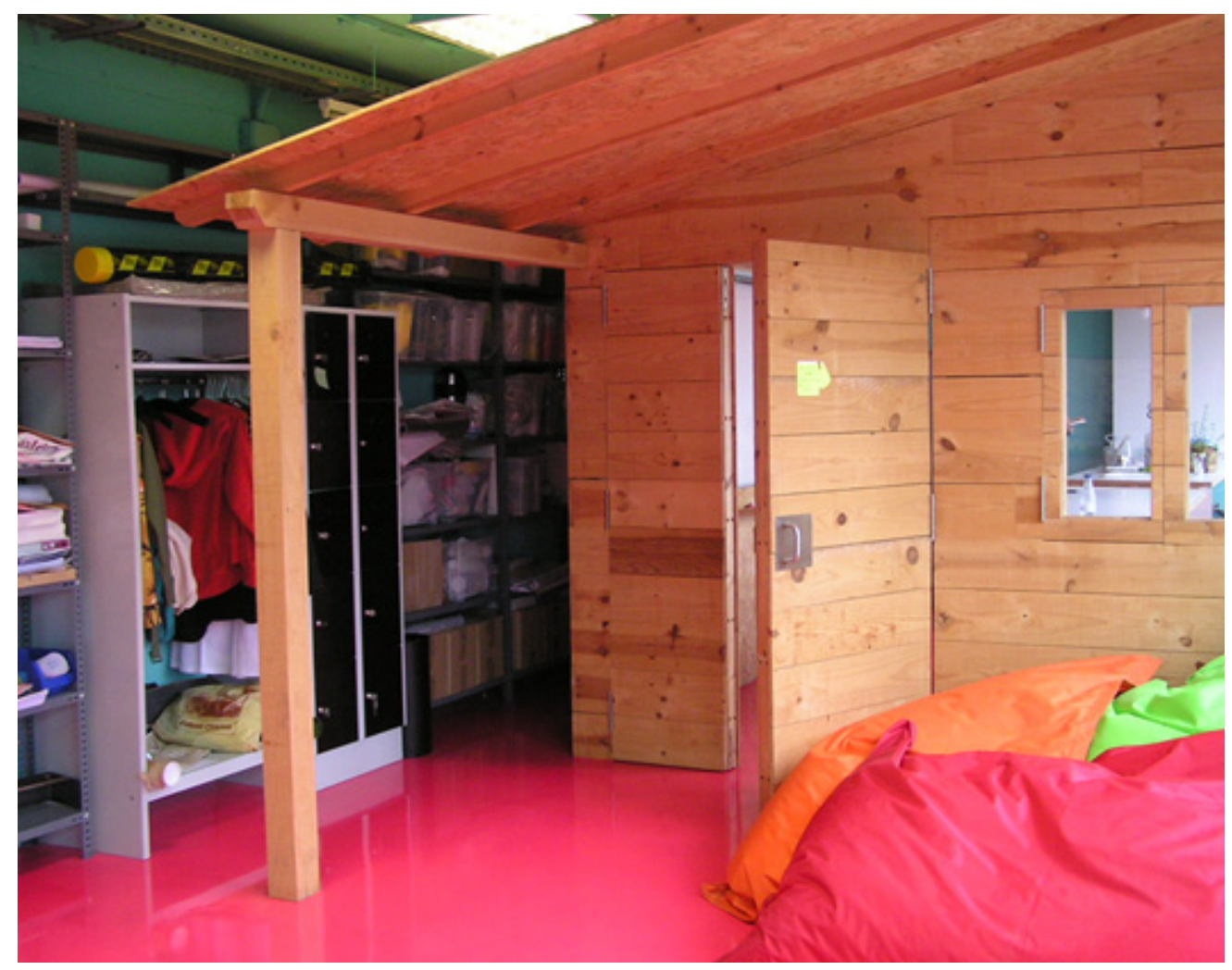

Imagen 1. Empresa del conocimiento en el País Vasco, en la que una estructura doméstica, una cocina y un espacio de reposo (a la derecha, cojines gigantes en los que descansar) se integran en el mobiliario de una oficina con diseño postindustrial y dotada de tecnología punta. Fuente: Elaboración propia. 
El desarrollo de la portabilidad y las tecnologías de la información posibilitan además una movilidad laboral sin precedentes que trasciende los muros de la empresa y los horarios laborales. Las grandes empresas tecnológicas no solo incentivan que el trabajador desarrolle sus propios proyectos creativos durante su jornada laboral, sino que también fomentan y premian la flexibilidad y la movilidad que sienta las bases para la implantación del teletrabajo. Como colofón, la propia cultura empresarial incentiva un espíritu contracultural, apasionado, rupturista, excéntrico e incombustible de sus trabajadores, sugiriendo una imagen más próxima al estereotipo de universitario que al del agresivo yuppie del pasado siglo (véase Reygadas et al. 2012).

En el proceso productivo, las cadenas de creación de valor cobran una mayor relevancia, estableciéndose sinergias no solo entre trabajadores y agentes externos (consumidores, usuarios, distribuidores, etc.), sino también entre humanos y sistemas expertos (Latour, 2008). En este contexto también cobra relevancia la ideación cooperativa y el capital social, mediados por las nuevas tecnologías de la información (Benkler, 2006; Botsman y Rogers, 2010), porque de la interacción entre sujetos brotan nuevas ideas para diseñar productos y servicios innovadores (véase Valenzuela-García et al., 2015). Queda atrás aquel obrero industrial relegado a mero apéndice de la máquina. Las empresas, en este contexto, apuestan por profesionales altamente cualificados, capaces no solo de tomar decisiones sino también de conectar saberes, subjetividades y experiencias en redes horizontales, abiertas y flexibles, con el propósito de generar conocimiento con alto valor añadido. Emerge, en este contexto, lo que Richard Florida (2010) acuña como clase creativa, un colectivo altamente cualificado que desempeña su actividad laboral en el campo del conocimiento: investigación, docencia, ingeniería, arquitectura, diseño, actividades artísticas, ocio y entretenimiento, profesionales de la salud, economistas y abogados (véase Mateos y Navarro, 2014). Su función económica, escribe Florida, "consiste en crear nuevas ideas, tecnologías y servicios" (2002: 8).

El trabajo, para esta clase creativa, a menudo es una pasión, un fin significativo en sí mismo, un desafío constante que proporciona satisfacción y contribuye al desarrollo personal. No obstante, debido a la ubicuidad de las tecnologías portátiles (computadoras personales, teléfonos móviles); a la organización de los encargos productivos por entregas y objetivos (dead-lines) y a un constante proceso de enseñanza/aprendizaje, el desempeño laboral suele traducirse en largas y extenuantes jornadas que trascienden el horario y el espacio de la oficina, extendiéndose sobre el tiempo libre, las vacaciones y los fines de semana. Esto contribuye a diluir las fronteras entre lo laboral y lo personal, entre la casa y la oficina, entre los hobbies y las obligaciones, difuminándose hasta el punto que no se sabe cuándo comienza una cosa ni acaba la otra (Hochschild, 2012, 1997).

La clase creativa desarrolla esa "clase de trabajo que te mantiene pegado al ordenador hasta altas horas de la madrugada, sin que apenas me dé cuenta que ha pasado la hora 
de irse a dormir" (Florida, 2010: 146). Y ahí radica el riesgo y la clave de su gestión, puesto que la creatividad del trabajador, con sus dimensiones laborales y vitales, son engullidos por la lógica extractiva del capitalismo (Ross, 2003). La antigua disciplina fabril, como mencionaba antes, da paso a un control normativo, "blando", por el cual son los propios trabajadores quienes se exigen y se presionan al máximo, guiados por una pasión vocacional que favorece sin embargo la proliferación de workaholics y perfeccionistas, alimenta el estrés y los burn-out y amenaza constantemente con descuidar la vida familiar. El control y la gestión de la producción se efectúa mediante lo que Michel Foucault denominó tecnologías del yo: prácticas de subjetivación que permiten a los individuos ejecutar operaciones de monitorización sobre sí mismos (Kelly, 2013). Y esa autodisciplina - forjada mediante una larga trayectoria en un sistema educativo meritocrático y competitivo que premia valores como la responsabilidad y el sacrificioabona el contexto para desplegar de modo efectivo el teletrabajo. De hecho, lograr ser productivo a distancia es difícil sin un elevado grado de compromiso y responsabilidad personal. Este compromiso se halla típicamente en el trabajo significativo, una actividad profesional que proporciona trascendencia, interés y libertad al profesional que la realiza (Scace, 2002). Por esa razón suele darse en las profesiones vocacionales y que implican mayor formación: profesores, psicólogos, diseñadores, puestos de dirección, etc. A diferencia de otras profesiones, como mencionábamos en otro lugar (Valenzuela, 2021), estas entrañan tanto un privilegio como un riesgo: un privilegio porque, en muchas ocasiones, uno se dedica a lo que más ama. Pero un riesgo porque,

"mediante la autogestión estos empleados se convierten en sus propios empleadores, quizás los más exigentes, que se autoimponen el control laboral tanto en el hogar como en su tiempo libre, descuidando su vida personal y familiar. Esto puede resultar en problemas de salud, abuso de sustancias, colapso mental" (Valenzuela et al., 2015: 192).

La emergencia del teletrabajo no sería comprensible sin el desarrollo del capitalismo cognitivo, pero tampoco sin la tendencia exacerbada a abaratar costos laborales y productivos en aras del beneficio.

En 1967, una empresa alemana de fabricación aeroespacial propuso por primera vez un horario laboral flexible para reducir los costes de desplazamientos de los empleados y aumentar su desempeño. Este programa inspiró a Hewlett-Packard para introducir una opción similar en sus instalaciones de en Alemania y Estados Unidos. Paralelamente, el Departamento de Defensa de Estados Unidos creó el primer prototipo funcional de Internet para conectar diferentes computadoras en red. Poco después, empresas de todo el mundo empezaron a experimentar con diferentes modelos remotos orientados a incrementar la eficiencia y la productividad de sus trabajadores. Sin embargo, el término "teletrabajo" fue acuñado en 1972 por Jack Nilles, un especialista en comunicaciones que 
trabajaba para la NASA. Nilles desarrolló un modelo de trabajo remoto para minimizar la congestión del tráfico y promover la conservación de recursos. Su iniciativa fue acogida con entusiasmo y en 1978 el gobierno de los Estados Unidos regularizó el trabajo flexible entre sus empleados federales. A finales de los años 70, en plena crisis del crudo, Frank Schiff acuñó el término de flexplace en un influyente artículo que publicó en el Washington Post con el título "Working From Home Can Save Gasoline." El artículo introdujo por primera vez el término de teletrabajo como hoy lo entendemos (trabajo remoto desde casa), inspirando poco después la primera conferencia sobre esta temática, en 1980 (Messenger et al., 2017).

Durante los años 90, la revolución de los teléfonos móviles, la evolución de la conectividad de los dispositivos informáticos y de los protocolos de transmisión (TCP, IP, HTTP), el despegue imparable de la rentable industria de los call-centers y el lanzamiento del sistema operativo Windows revolucionaron para siempre la informática personal y empresarial. En 1992 se implantó un proyecto piloto de teletrabajo entre las distintas agencias gubernamentales en Washington D.F. En 1996 se desarrolló la Iniciativa Nacional de Teletrabajo y, en 2004, el Congreso impulsó un proyecto de ley que fomentaba el uso de acuerdos de trabajo remoto dentro de las agencias federales. En 2008, Microsoft lanzó la tecnología Smooth Streaming, que potenció la transmisión de datos en las empresas; y con la expansión de Internet, el aumento de la banda y la capacidad de la nube, la expansión de los dispositivos portátiles, la ubicuidad y creciente asequibilidad de los smartphones, y la proliferación de plataformas de teletrabajo y de software colaborativo (Upwork, Virtual Vocations, Zoom, Skype, Slack, Hootsuite, Asana, Teams, etc.), se sentaron las bases infraestructurales para lanzar el teletrabajo a gran escala (véase Messenger et al., 2017; Wendell, 2000).

El boom del teletrabajo llegaría poco después, significativamente tras la crisis financiera, en 2009. Para entonces, más de 100.000 empleados federales estaban trabajando de forma remota. En la última década, el teletrabajo se ha incrementado entre un 100\% y un $140 \%$ en el mundo y, a partir de la pandemia de la covid-19, se ha convertido en la norma para millones de trabajadores. Actualmente, aunque existe una amplia variabilidad entre países, alrededor del 25\% del empleo en la Unión Europea se realiza desde el hogar, mientras que antes de la pandemia apenas alcanzaba el 15\%. Puesto que la implantación de esta modalidad de trabajo incentivará a su vez el desarrollo de las tecnologías de la información y las comunicaciones, es previsible una verdadera revolución laboral a medio plazo (Messenger et al., 2017).

\section{METODOLOGÍA}

Con el propósito de conocer mejor tanto el perfil del teletrabajador en el contexto de pandemia como sus percepciones y expectativas, durante el primer confinamiento se administró una encuesta online que obtuvo 66 respuestas válidas. La encuesta contenía 
veinte preguntas sobre cuestiones socio-demográficas (sexo del respondiente, franja de edad, nivel de estudios, situación familiar, área profesional y tipo de trabajo) y preguntas abiertas referentes a la valoración del trabajo actual y a la percepción del teletrabajo antes y durante la pandemia (frecuencia, valoración, compaginación vida/trabajo y expectativas).

La muestra fue aleatoria y el criterio de inclusión amplio y poco selectivo: personas cuya actividad laboral se hubiese expuesto a teletrabajo durante (y a consecuencia de) la pandemia. Puesto que se trataba de una encuesta exploratoria, inicialmente se partió de un grupo de lazos débiles: fundamentalmente, compañeros de trabajo, padres y madres de alumnos de la escuela local, etc. Estos, a su vez, contactaron con sus conocidos, la mayoría circunscritos a Cataluña. De modo que, para captar encuestados, se siguió una estrategia de bola de nieve: a los primeros contactos se les pidió que contestasen la encuesta de modo anónima y la reenviasen a su vez a tres de sus contactos personales que se encontrasen en la misma situación; y así sucesivamente. La mayoría de respuestas se recopiló en Cataluña y se detecta un sesgo importante de género (aproximadamente un $75 \%$ de los respondientes fueron mujeres).

La encuesta era exploratoria y no anhelaba representatividad estadística. A pesar del escaso número de respuestas, que nos previene de la posibilidad de realizar amplias generalizaciones o extrapolaciones, los datos se han comparado con otras encuestas publicadas en la prensa y con informes oficiales de la Unión Europea, mostrando un considerable grado de congruencia.

\section{TELETRABAJADOR TIPO: UN SEMBLANTE APROXIMADO}

La implantación del teletrabajo tiene una distribución desigual en varios sentidos. En esta sección trataremos de mostrar esas irregularidades siguiendo una lógica analítica que va desde lo general (distribución del teletrabajo en los países de la UE) hasta lo concreto (praxis cotidiana del teletrabajo en España durante el confinamiento).

En el espacio de la UE, la extensión del teletrabajo muestra, en primer lugar, una diferencia notable entre países, particularmente entre los estados nórdicos, centroeuropeos y el resto (mediterráneos, del sur y aquellos que se incorporaron más tarde a la UE, por lo general con menor PIB). En 2019, el 30\% de los empleados en Dinamarca, Suecia, Finlandia o los Países Bajos desempeñaban sus tareas laborales desde casa de manera esporádica o habitual, mientras que en la mitad de los estados miembros de la UE este porcentaje apenas llegaba al 10\%. En los primeros, no solo estaba el teletrabajo más extendido antes de la pandemia, sino que durante la pandemia también registró una mayor expansión que en el resto de los países. Esta distribución desigual del teletrabajo se relaciona además con el grado de desarrollo de los sectores industriales, con las políticas y estrategias de innovación tecno-económica adoptadas por las distintas economías nacionales, y con el 
grado de autonomía y confianza que se les confiere a los trabajadores del conocimiento en los distintos países e industrias. Así, por ejemplo, en Suiza, los Países Bajos o Finlandia, tanto el volumen de trabajadores como el número de empresas dedicadas a la industria del conocimiento era, antes de la pandemia, marcadamente superior al hallado en Portugal, Italia o Croacia. En 2018 solo teletrabajaba de manera habitual el 40\% de los empleados en Francia, el 32\% en Alemania y el 11\% en Italia, mientras que en Suecia lo hacía un 70\%. En la misma línea, mientras que el 37\% de los trabajadores finlandeses había recibido formación en TIC, en Rumanía apenas llegaba al 6\% (Comisión Europea, 2020).

La desigualdad se reproduce también internamente: en la distribución geográfica del trabajo remoto, que se concentra en las regiones urbanas y periurbanas, más ricas, con más renta y con mayor grado de innovación y desarrollo tecnológico (Mateos y Navarro, 2014). Esto coincide con la distribución de la clase creativa observada por Florida (2002). En el caso de España también la incidencia del teletrabajo es mayor en Madrid, País Vasco y Cataluña que en el resto de las Comunidades Autónomas (Maqueda, 2020) y se concentra particularmente en las zonas urbanas.

Por sectores, como hemos visto, en el contexto de la UE la incidencia del teletrabajo era marcadamente superior en la industria de las TIC, en el sector de las telecomunicaciones, las finanzas y las aseguradoras. Con la pandemia, el teletrabajo se extendió inmediatamente al sector educativo, entre autónomos y profesionales liberales y fue ampliamente adoptado por gerentes altamente calificados (particularmente en el ámbito legal, comercial, administrativo y científico), trabajadores de la administración pública y la sanidad, ingenieros, informáticos y expertos en marketing digital (Maqueda, 2020). A pesar de esa tendencia, en el caso de España, con una economía altamente "terciarizada" (74.2\%) y orientada a empleos que requieren una elevada presencialidad y mano de obra intensiva (almacenaje, comercio minorista, turismo, transporte, agricultura, hostelería o construcción), el teletrabajo ha tenido una expansión limitada en comparación con otros países de la UE.

En el contexto empresarial también se advierte una diferencia notable. La implantación del trabajo desde casa se dio con mayor frecuencia en las grandes empresas (con más de cincuenta empleados), que contaban con infraestructuras de TIC adecuadas. Pero mientras que para estas esta opción podría suponer un importante abaratamiento y ahorro de costes (en términos de gasto energético, limpieza, tiempo de transporte de empleados, dotación de servicios para empleados, etc.), para muchas PYMES (que constituyen el principal tejido empresarial en España) la inversión infraestructural supuso un gasto insostenible (Aranda, 2020). Tampoco un elevado porcentaje de autónomos, muchos de ellos pequeños empresarios con pocos trabajadores a su cargo, han podido asumir los costes. En las medianas y pequeñas empresas algo más solventes que implantaron el 
teletrabajo, el retorno a la empresa tras el verano implicó una importante reconversión de la infraestructura en forma de reducción de la capacidad de las oficinas (entre un $35 \%$ y un 50\%), adopción de medidas sanitarias, protocolos de desinfección, gestión de residuos, rutinas de limpieza, control sanitario y de temperatura, establecimiento de turnos o limitación de los aforos en los espacios comunes (ascensores, restaurante o servicios) (Medel Vicente, 2020).

Las profesiones en las que el trabajo remoto es habitual suelen estar más remuneradas y sus trabajadores gozan de un mayor grado de autonomía. A este respecto, el informe de la Comisión Europea (2020) expone lo siguiente:

"Como reflejo de la mayor prevalencia del teletrabajo entre los trabajadores altamente calificados, el acceso al teletrabajo estaba considerablemente más extendido entre las personas bien remuneradas. De hecho, alrededor del 25\% de los trabajadores de la mitad superior de la distribución de ingresos de la UE-27 teletrabajaban en 2018, una proporción que se reduce a menos del 10\% entre los de la mitad inferior (fuente: Eurostat, encuesta sobre el uso de las TIC). A medida que la pandemia exacerba la división entre quienes pueden pasar fácilmente a trabajar desde casa y quienes no, la desigualdad aumentará, comenzando desde los niveles altos. Los ingresos mensuales medios de los gerentes y profesionales, personas que ahora trabajan principalmente desde casa, son en promedio más del doble de los ensambladores y operarios de máquinas [y trabajos que implican manipulación física de materiales, manufacturas y logística], que en su mayoría trabajan en planta" (Comisión Europea, 2020).

Según Eurostat, en 2018 tan solo el 4,3\% de los empleados españoles reconocía trabajar desde casa con regularidad. Paradójicamente, en la UE, los países más afectados por la pandemia son también los que registran una menor presencia de teletrabajo. Y esta diferencia en la prevalencia también refleja otras desigualdades en términos de calidad de vida (Suiza, Dinamarca o Alemania en los puestos altos de la clasificación; mientras que España, Italia, Portugal, Grecia y Estonia se hallan en la cola); duración de la jornada laboral (a la cabeza, en horas, Grecia, Malta, Polonia y Portugal); horquilla salarial (Luxemburgo, Bélgica, Países Bajos o Alemania por delante y España, Malta, Grecia y Portugal en un nivel medio-bajo), o el grado de desempeño educativo, que en España se sitúa por debajo de Italia (28), Francia (20), Irlanda (16) o Polonia (5) (OCD, 2018). En ese contexto España "no es sólo el país de la UE donde hay mayor precariedad, sino que es también el país donde el crecimiento de la precariedad ha sido mayor durante el periodo 2010-2015" (Navarro, 2018). En el otro extremo, volvemos a hallar a los países nórdicos de la UE: Suecia, Finlandia y Dinamarca.

Si nos centramos en el perfil de los teletrabajadores derivado de nuestra encuesta, los datos coinciden con la realidad europea. De acuerdo con nuestros datos, el 22\% (15) de los 
encuestados se situaba en la franja de edad de entre los 51 y los 60 años. Aproximadamente la mitad (48\%, 32 personas) tenía una edad comprendida entre los 41 y los 50 años, 17 (25\%) entre los 31 y los 40 y sólo dos personas entre los 21 y los 30 años. Por lo tanto, el teletrabajo se concentra en las franjas laborales senior.

Los encuestados también muestran un nivel formativo excepcionalmente elevado. El 90\% (60 personas) había llevado a cabo estudios superiores. De estos, el 58\% (35) contaba con títulos de grado o licenciaturas universitarias y el $42 \%$ (25) con postgrados universitarios (máster o doctorado). El resto, 6 personas, había efectuado estudios técnicos o profesionales especializados y superiores.

La distribución por sectores laborales en España mostraba una elevada incidencia en el sector educativo (un 47\%): 31 encuestados se dedicaban a la educación (desde magisterio a profesorado universitario y de formación profesional). El siguiente sector en volumen obedecía a administrativos, funcionarios y gestores de empresa (13 personas, 19\%); seguido de siete industriales y técnicos superiores (10\%); seis trabajadores del ámbito sanitario (9\%); cinco empleados del sector de las telecomunicaciones y la informática (7,5\%); y cuatro comerciales de seguros y trabajadores del ámbito del e-comerce (6\%). La mayoría (90\%) eran asalariados con empleos fijos o indefinidos y solo 6 (10\%) eran autónomos. Y también la mayoría (89\%) contaba con experiencia previa de teletrabajo (ya fuera de manera ocasional o regular), lo cual no es del todo extraño, teniendo en cuenta el alto porcentaje de individuos dedicados a la enseñanza y a la investigación, que implica la realización de gran parte de las tareas en casa: preparación de clases, corrección, lecturas, informes, evaluación, etc. La mayoría de estos trabajadores gozaban de elevada autonomía y ocupaban puestos de responsabilidad, lo cual también redunda en mayores ventajas laborales y salariales. Todos estos indicadores muestran gran congruencia con lo hallado en Europa y con los trabajos de Florida (2011, 2002, 2010).

Entre las ventajas, lo que más valoraban de su trabajo estas personas era, en primer lugar, la autonomía, la creatividad y el desarrollo personal (el 31\%, 21 respuestas). En segundo lugar (28\%), valoraban razones prácticas, como el horario, la proximidad o la facilidad para trasladarse a su puesto laboral. En tercer lugar (13 respondientes, 19\%) valoraban las relaciones, el ambiente y el contacto personal en el lugar de trabajo. Nueve (13\%) valoraban ante todo las compensaciones salariales; tres la experiencia que les había proporcionado su empleo y uno la seguridad laboral. Respecto a las ventajas del teletrabajo en tiempos de pandemia, el 33\% (22) valoraba la flexibilidad (en términos horarios, de autonomía, autogestión tiempo y planificación de las tareas); el 30\% (20 personas) la posibilidad de pasar más tiempo con la familia y, en el caso de personas sin hijos, la mayor disponibilidad de tiempo libre. El 27\% (18 personas) valoraba el ahorro de tiempo y costes de transporte; aunque 6 personas (9\%) no hallaban ninguna ventaja en el teletrabajo. 
Entre las desventajas percibidas del teletrabajo durante la pandemia, el 34\% señalaba la falta de relaciones sociales y el sentimiento de soledad. El 33\% de los encuestados señalaba la dificultad de imponer límites a su dedicación laboral, la sensación de autoexplotación (o, como expone un respondiente, "estar permanentemente conectado al trabajo"). Como apuntaba una encuestada, "[el problema es que] no hay jornada de trabajo, ¡es todo el día!”; y otro participante aducía: “trabajo más de 12 horas: esto no es humano". En estas condiciones, más horas no siempre significaba mayor productividad: "la efectividad cae y eso implica estirar el día por la mañana o por la noche, aumentando el cansancio", escribía un encuestado. En el mismo sentido, un encuestado se lamentaba del hecho de tener que "alargar la jornada para contrarrestar la caída de la eficiencia". "Mucho ordenador y nada de vida", escribía otro participante. Vinculado con esto último, un $10 \%$ (7 personas) consideraba que la principal desventaja de trabajar en casa era la dificultad para concentrarse. Una dificultad que, a medio plazo, generaba frustración y desmotivación. Otro 10\% consideraba que el problema principal era establecer fronteras entre las tareas domésticas y profesionales, ocasionando sensaciones de "caos", "desorden", "anarquía” o "frustración". Cuatro personas (6\%) consideraban que la principal desventaja derivaba de estar expuesto a una disponibilidad constante forzada por las tecnologías móviles (smarthphones, fundamentalmente) que dificultaban realizar las tareas de forma continua y eficiente. Una persona denunciaba la falta de reconocimiento en esas circunstancias por parte de sus superiores; y otra consideraba que la principal desventaja era el uso de recursos propios (tóner, papel, Internet, calefacción, luz, etc.).

Respecto a la composición doméstica, el 63\% (42 encuestados) vivía en pareja con hijos; el 16\% (11 personas) vivía en pareja, pero sin hijos. Nueve individuos (13\%) vivían solos y sin hijos, mientras que 4 individuos (el 6\%) vivían solos y tenían hijos a su cargo (ya fuera en soltería o debido a separaciones o viudedad).

Como se señalaba antes, una de las grandes desventajas percibidas del teletrabajo en tiempos de pandemia reside en la dificultad para separar el ámbito doméstico del laboral o, en otros términos, la esfera productiva (trabajo remunerado) de la reproductiva (trabajo doméstico no remunerado). Sin embargo, esta percepción muestra diferencias sustanciales en función de la composición del hogar.

En el caso de parejas sin hijos, a pesar de la sobrecarga, se enfatiza la flexibilidad y la libertad como aspectos positivos: "trabajo de 9 a 17:30 aproximadamente y después aprovecho para hacer cosas en casa y estar con mi pareja. [Pero] soy flexible. A veces empiezo más tarde a trabajar para ir a hacer deporte temprano o a comprar". Sin embargo, la percepción varía radicalmente cuando hay hijos en el hogar: "[la situación] es difícil ya que trabajando con los hijos y teniendo que hacer las tareas del hogar y hacer deberes... cuando no tengo el marido en casa es casi misión imposible”. En concreto, la mayoría de unidades domésticas con hijos subrayan, como principal desventaja, el estrés y, de nuevo, 
la dificultad para concentrarse y llevar a cabo actividades cognitivas: "en casa todo me distrae, necesito un espacio formal. Es alienante trabajar y vivir en el mismo lugar: no se puede enseñar desde casa", subraya una docente. La mayoría reconoce que trabajar en estas condiciones, particularmente si hay niños, requiere más esfuerzo y sacrificio.

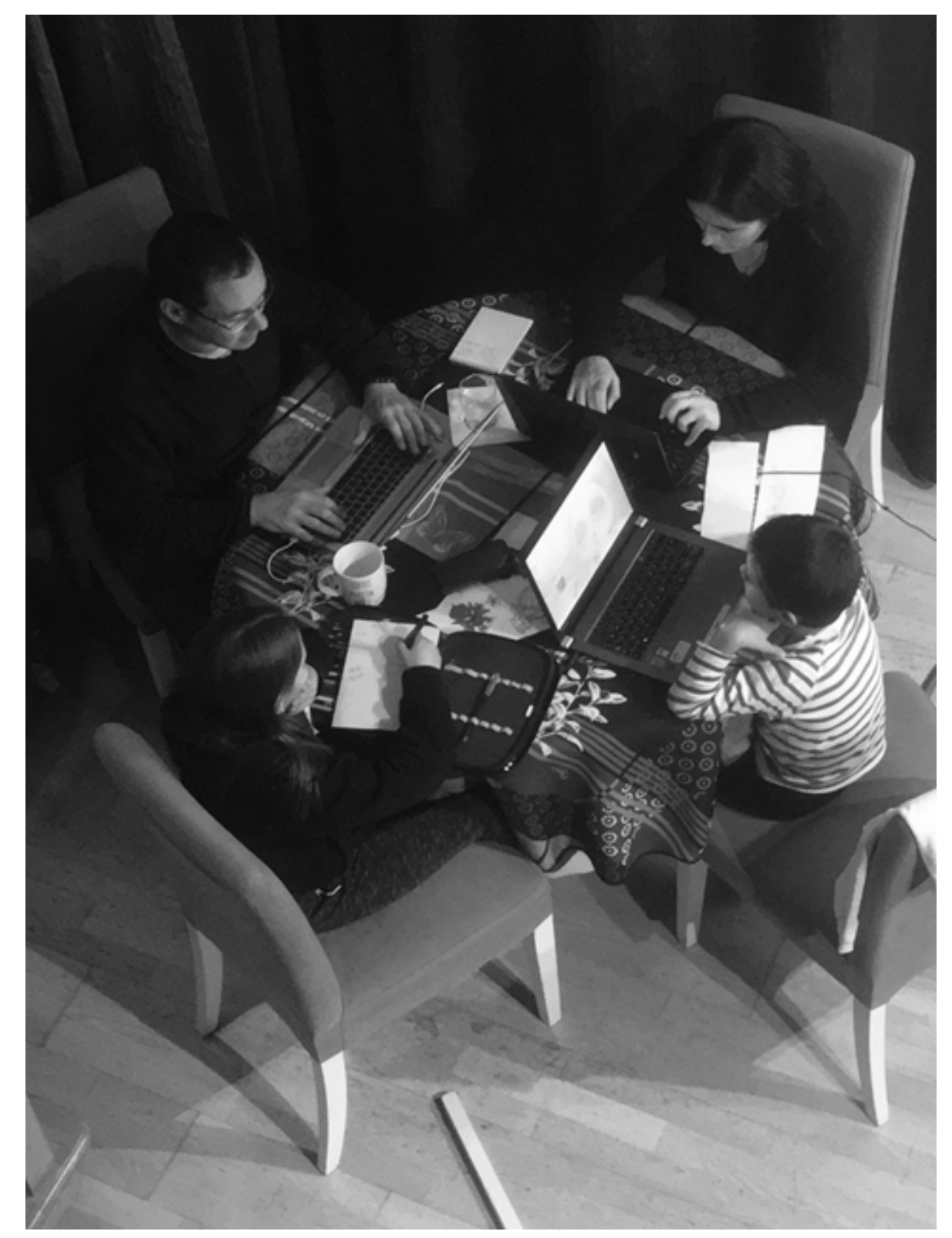

Imagen 2. Jornada habitual de teletrabajo en familia. Fuente: Elaboración propia.

En el caso de las parejas con hijos, para lograr un equilibrio entre la esfera doméstica y la laboral suele recurrirse a la delimitación de horarios y espacios de trabajo, por un lado, y a la redistribución equitativa de las tareas domésticas y cuidados del hogar, por otro. En algunos casos esta situación exacerba las tensiones en la pareja, sobre todo si ambos están empleados. Como apuntaba una encuestada:

"Es muy complicado. Niños pequeños (dos de menos de 4 años) y dos trabajos a tiempo completo. Hacemos turnos mayoritariamente para que haya alguien con 
ellas, además de levantarme muy temprano y acostarse tarde. Tienes la sensación de trabajar todo el día. La casa ... lo que se puede, la prioridad es que ellas estén bien [...]. Mi marido y yo tratamos de dividir las tareas domésticas, pero no siempre es posible $[\ldots]$ y en algunas ocasiones 'competimos' por el trabajo. Y discutimos".

De hecho, como también muestran otras encuestas, el desequilibrio de las tareas no se ha reducido con el confinamiento. Al contrario: las madres siguen llevando la mayor parte de la carga familiar y el cuidado de los hijos (Brunat, 2020). Como señaló una encuestada en una pregunta abierta:

"[Lo llevo] muy mal. Estoy muchísimas horas sentada delante del ordenador. Y el trabajo sale muy lento, muy despacio. Tengo muy descuidada la casa [...]. Lo he pasado muy mal durante estas semanas [mes y medio de confinamiento], muy angustiada. Ahora entiendo que llegaré hasta donde pueda".

Y toda esta situación se extrema cuando solo hay un adulto (madre o padre) a cargo de hijos. Como expone una madre soltera:

"En mi trabajo se acumula la carga administrativa. Mi hija me pide mucha atención y se acumula el trabajo. Intento tener tiempo por la tarde, para salir y hacer las tareas domésticas [...]. Pero es muy complicado. Con hijos en casa, trabajar, cocinar, estar por ellos [...], algunos días en francamente difícil. Muchas video-conferencias y reuniones virtuales. Muy estresante y cansado".

Otra mujer separada con una hija manifiesta un testimonio similar:

"El problema es trabajar y tener hijos desatendidos durante ocho horas. El trabajo implica muchas reuniones con Skype y cumplir plazos muy cortos que hacen incompatible poder educar o prestar atención a los hijos. Cuesta tener un horario que permita cierta normalidad".

En condiciones habituales, sin alerta sanitaria ni confinamiento, muchas de estas familias solían externalizar las tareas domésticas a otros familiares (a menudo los abuelos) o recurrían a asistentas domésticas y canguros. Incluso durante el confinamiento, tres encuestados se vieron forzados a recurrir a esta ayuda externa. Y esta división del trabajo vuelve a apuntar a una distribución desigual: lo que suele externalizarse es el trabajo de cuidados y de reproducción (el menos valorado económicamente) que, cuando es remunerado, suelen realizarlo otras mujeres menos cualificadas, mientras que se opta por desarrollar el trabajo productivo, asalariado y más significativo. Ese trabajo doméstico y de cuidado muy a menudo lo realizan mujeres inmigrantes, generalmente madres.

\section{AMPLIFICACIÓN DE LA DESIGUALDAD}

Como hemos observado, la distribución del teletrabajo durante la pandemia refleja una serie de desigualdades que atraviesan de extremo a extremo la estructura socioeconómica: 
desigualdades subyacentes entre países, regiones y sectores industriales, empresas, puestos laborales y franjas de edad, estatus socioeconómico, género y etnia. Sinteticemos esas cuestiones.

En primer lugar, como señalan los informes consultados, la implantación del teletrabajo refleja notables desigualdades estructurales entre los países miembros de la UE en términos de territorios y regiones, políticas económicas y sectores industriales, grado de tecnologización y estrategia a futuro, tamaño de las empresas o apuesta formativa de los empleados. Como decíamos, esta distribución del teletrabajo en la UE refleja otras desigualdades en cuanto a calidad de vida, condiciones laborales o grado de desempeño educativo.

La siguiente gran desigualdad deriva del acceso al trabajo mismo. La crisis financiera de 2008 tuvo efectos devastadores en términos de destrucción de empleo (la tasa de paro llegó al 25\%) e incremento de la pobreza y la desigualdad (García-Pérez, 2012), dejando al $18,4 \%$ de la población española (8,5 millones) estancado en la exclusión: 1,2 millones más que antes de la crisis. De estos, aproximadamente la mitad (4,1 millones) se encuentra en situación de exclusión social severa, con cerca de dos millones en situación de necesidad extrema (Fundación-FOESSA, 2019). Este sector, privado de empleo, a menudo está aquejado por una larga lista de males: falta de capital cultural y económico, redes sociales escasas y homófilas ${ }^{2}$, estado de salud deteriorado, adicciones, estado familiar vulnerable y fragmentado, etc. Para este sector social, las posibilidades reales de inclusión social y plena participación ciudadana son realmente escasas (véase Valenzuela-García et al., 2020). Y con el confinamiento su situación ha empeorado (García, 2020).

Por otra parte, se observa una desigualdad menos obvia, pero sin duda más alarmante, entre los empleados que han podido optar al teletrabajo y los que ni siquiera han tenido esa alternativa (Jiménez, 2020). Y sostenemos que esta desigualdad es más alarmante porque demuestra que la pobreza ya no es sinónimo de desempleo. Más de 6 millones de españoles, aunque forman parte de la sociedad integrada, adolecen de rentas fijas, tienen una participación irregular y precaria en el mercado de trabajo y su acceso a la vivienda, salud y pensiones no está en absoluto asegurada. Esta sociedad insegura agrupa a parados de larga duración, trabajadores temporales, jóvenes dispuestos a entrar en el mercado de trabajo, desempleados sénior, madres solteras, trabajadores no cualificados e inmigrantes, entre otros. Como señalan Baert et al. (2020),

"es posible que los beneficios del teletrabajo no estén disponibles para los no calificados o no capacitados [...], trabajadores en ocupaciones manuales o con

2. En el contexto del análisis de redes sociales, la homofilia remite a la similitud existente en una o más características relevantes entre los individuos de la red social que están interrelacionados entre sí. Es decir, en nuestro caso, el individuo comparte muchas características socioeconómicas con sus contactos. 
escasas habilidades digitales que, ya antes de la pandemia, se encontraban entre los segmentos de la fuerza laboral con salarios más bajos. A medio plazo, la pandemia de Covid-19 tiene el riesgo de exacerbar aún más las desigualdades existentes, pues estos trabajadores son los que tienen más probabilidades de perder sus empleos, experimentar reducciones de horas laborales y sufrir una gran incertidumbre en cuanto a ingresos".

Este creciente colectivo no es una particularidad de nuestra sociedad. En el Reino Unido, Guy Standing define a ese estrato social como precariado (Standing, 2011) y en Estados Unidos, Newman y Chen (2007) describen una realidad similar:

"Cincuenta y cuatro millones de estadounidenses son "casi pobres", incluido uno de cada cinco niños, y viven en hogares con ingresos entre $\$ 20,000$ y $\$ 40,000$ en familias de cuatro miembros. Viven por encima del umbral de la pobreza, pero a solo un desliz, un divorcio o una crisis de salud, del límite. Y es menos probable que tengan una cuenta de ahorros o sean propietarios de una casa $u$ otro activo que atenúe el golpe de una crisis financiera” (Newman y Tan Chen, 2007: ix).

La disponibilidad de capital cultural (formación y educación formal) consuma la desigualdad, pues la extensión del teletrabajo es complicada en las actividades que implican un elevado grado de interacción cara a cara con el público (por ejemplo, vendedores, trabajadores de servicios personales) y en aquellas profesiones que requieren presencia física y mano de obra intensiva (almacenaje, la logística, el comercio minorista, turismo, transporte y hostelería, ocio, hospitales, supermercados y servicios básicos). Estos sectores se han expuesto particularmente a una creciente desregulación que ha aumentado la temporalidad de los contratos al 26,8\% de media y al 73,3\% entre los jóvenes (Eurostat, 2018). Durante la pandemia estos sectores han sido los más castigados por los despidos y los ERTES. Los servicios de limpieza, los operadores de venta telefónica y la distribución online suponen la excepción porque el empleo se ha intensificado en esos sectores, pero se trata de nichos muy precarizados cuyo salario oscila entre los 7,39 y 8,86 euros brutos la hora (Sánchez, 2020).

En contraposición a esa realidad desoladora, hallamos a los teletrabajadores. Este colectivo, como hemos mencionado, respondería a la clase creativa (Florida, 2002): empleados con mayor capacitación y formación, con profesiones que implican más responsabilidad y requieren la aplicación intensiva de conocimiento: "personas especializadas en diseño, educación, arte, música y entretenimiento, cuya función económica es crear nuevas ideas, nuevas tecnologías y contenido creativo" (Florida, 2002: 8). Su porcentaje se ha incrementado exponencialmente, particularmente en las economías avanzadas: en Singapur suponen el $47.3 \%$, en Suiza el $44.8 \%$, en Alemania el $41.7 \%$ y en España se estima que rondaría el 30\%. Este colectivo ha sido masivamente transferido a un entorno doméstico y remoto, pero incluso ese contexto no está exento de desigualdades. 
De acuerdo con los datos recabados en la encuesta, y en sintonía con los datos generales de los informes de la UE, podemos afirmar que el teletrabajo se concentra en las franjas senior, más cualificadas y mejor remuneradas de sectores dedicados a la industria del conocimiento de manera más general. Además, se concentra entre en los trabajadores indefinidos, con mayor experiencia, salarios y cualificación. El teletrabajador tipo goza de elevada educación (estudios técnicos especializados, universitarios y posuniversitarios) y es un asalariado sénior que desarrolla su actividad laboral en el ámbito educativo, gestión y administración empresarial, sector sanitario, TIC y mercadotecnia, con previa experiencia en el trabajo desde casa. A pesar de las circunstancias, los teletrabajadores señalan los siguientes aspectos positivos en el ejercicio habitual de su profesión: la autonomía y libertad, los incentivos materiales y prácticos (horario, proximidad, etc.), las relaciones laborales, las compensaciones salariales y la experiencia laboral. Y durante la pandemia, a pesar de que las condiciones no eran ideales, valoraban la flexibilidad, la posibilidad de pasar más tiempo con la familia y el ahorro de tiempo y costes de transporte. Entre las desventajas del teletrabajo en tiempos de pandemia, destacan la ausencia de relaciones sociales, la dificultad para establecer límites entre el trabajo y la vida, el aumento de la carga laboral y la caída del rendimiento, al margen de una minoría que denunciaba las dificultades logísticas o infraestructurales del trabajo doméstico (uso de recursos propios, interrupciones debido a la ubicuidad tecnológica, etc.).

En cuanto a la composición familiar y residencial, según nuestros datos, el 63\% vivía en una unidad doméstica con su familia nuclear (pareja e hijos), seguido de parejas sin hijos, individuos solos e individuos a cargo de hijos. A este respecto, la dificultad para desarrollar su actividad laboral en tiempos de pandemia parece correlacionarse con esa situación y con la presencia de hijos; es decir, los que solían encontrar más problemas para conciliar vida y trabajo eran, por orden, primero los padres y madres solos a cargo de hijos; segundo, las parejas con hijos y, finalmente, las parejas sin hijos e individuos sin cargas familiares. La división del trabajo sugiere así una desigualdad en cascada: en el caso de parejas, la mayor carga recae sobre la mujer, en los casos de progenitores aislados recae la doble carga laboral y doméstica; y en el caso que se externalice el trabajo doméstico (recurriendo a parientes o contratando a asistentas) se prioriza el trabajo productivo, vocacional y remunerado y se externalizan los trabajados de cuidados domésticos, menos creativos, que suelen transferirse a trabajadoras informales, poco remuneradas y, con frecuencia, migrantes. Estos parámetros que sugieren desigualdad de clase, ética y de género.

\section{CONCLUSIONES}

En España, la implantación del teletrabajo a gran escala ha venido forzada por el contexto de alarma sanitaria y la urgencia socioeconómica. Su implantación repentina fue imprevista y su ejercicio anómalo: los teletrabajadores, confinados en el contexto 
doméstico, tuvieron que asimilar una realidad laboral a distancia sin recursos ni preparación y a cargo de sus hijos en ausencia de escuelas. En definitiva, aunque esta premura haya posibilitado salvar a empresas y puestos laborales, el coste ha sido elevado y ha mostrado una realidad que dista mucho del ideal utópico que algunos barajaban. En las condiciones de confinamiento en las que se llevó a cabo la encuesta sobre teletrabajo, los aspectos negativos percibidos parecen superar a las ventajas. Resulta significativo que la mayoría de los encuestados (52 casos, el 78\%) coincidiese en que el trabajo remoto implica un aumento considerable de la carga laboral. Este dato concuerda con otras encuestas realizadas por consultores, que señalan que menos de un $35 \%$ de los trabajadores está a favor de continuar teletrabajando (Aranda, 2020; Brunat, 2020). De acuerdo con una encuesta realizada a 14.005 teletrabajadores flamencos (Baert et al. 2020), el $85 \%$ consideraba que el teletrabajo había llegado para quedarse y el $81 \%$ pensaba que las reuniones virtuales y las conferencias digitales pasarían a formar parte de su práctica laboral habitual en el futuro. Sin embargo, muchos manifestaban incerteza ante el futuro laboral y temían perder sus trabajos o que disminuyesen las oportunidades de promoción interna.

Esta implementación experimental del teletrabajo durante la pandemia presenta muchos retos socio-antropológicos. Para empezar, la radiografía de su implantación sugiere una preocupante amplificación de la desigualdad estructural en términos de países, territorios, sectores, puestos laborales, salarios, edad, etnia y género. Y empleamos aquí el término sugiere porque todas estas observaciones son preliminares y exploratorias; porque se requerirían más datos y un muestreo más amplio y cuidadoso; y porque el diseño metodológico requeriría de una mirada más antropológica y una observación más incisiva. A pesar de esto, el teletrabajo parecer ser una variable fundamental para la realización de previsiones socioeconómicas a medio plazo. Es más, el acceso al teletrabajo se presenta como un indicador clave para guarecerse de las fauces de la desigualad: ¿nos hallamos ante un darwinismo social de nuevo cuño? La política debería tomar nota de estas tendencias en un innegable escenario de creciente polarización social. Aunque los análisis macro indican que este proceso es estructural o global, los datos resultan particularmente alarmantes en el caso de España, que se encuentra en el percentil más bajo en todos los indicadores de la UE; ocupa el último puesto en indicadores cruciales como la calidad laboral; puntúa muy bajo en desarrollo tecnológico y formación en competencias TIC. Ojalá este análisis y su previsión sean erróneos. 


\section{REFERENCIAS BIBLIOGRÁFICAS}

Aranda, José Luis (2020) “Trabajo: las oficinas tardarán en volver a ser como antes". Disponible en: https://elpais.com/economia/2020-05-03/las-oficinas-tardaran-envolver-a-ser-como-antes.html [Consultado el 4 de mayo de 2020].

Baert, Stijn, Louis Lippens, Eline Moens, Philippe Sterkens y Johannes Weytjens (2020) "How do we think the COVID-19 crisis will affect our careers (if any remain)?". GLO Discussion Paper Series 520, Global Labor Organization (GLO).

Benkler, Yochai (2006) The wealth of networks. How social production transforms markets and freedom. New Haven: Yale University Press.

Botsman, Rachel y Roo Rogers (2010) What's mine is yours. The rise of collaborative consumption. Nueva York: Harper Collins.

Boyer, Robert (1992) La teoría de la regulación: un análisis crítico. Valencia: Edicions Alfons el Magnànim.

Brunat, David (2020) "Padres al borde de un ataque de nervios: queríamos teletrabajo, no esclavitud". Disponible en: https://www.elconfidencial.com/amp/espana/2020-05-15/ padres-teletrabajo-empresa-colegio-septiembre_2595844/ [Consultado el 15 de mayo de 2020].

Doncel, Luis (2020) "España no volverá al nivel de paro previo a la pandemia hasta 2026, según el FMI". Disponible en: https://elpais.com/economia/2020-10-13/espanano-volvera-al-nivel-de-paro-previo-a-la-pandemia-hasta-2026-segun-el-fmi.html [Consultado el 4 de Diciembre de 2020].

European Comission (2020) "Telework in the EU before and after the COVID-19: where we were, where we head to". Disponible en: https://ec.europa.eu/jrc/sites/jrcsh/files/ jrc120945_policy_brief_-_covid_and_telework_final.pdf [Consultado el 6 de Diciembre de 2020].

Eurostat (2018) "Employment and unemployment". Disponible en: https://ec.europa.eu/ eurostat/web/lfs/data/database [Consultado el 8 de Diciembre de 2020].

Florida, Richard (2011) “The world's leading creative class countries. The U.S. has fallen far behind in this key measure of human capital". Disponible en: https://www. bloomberg.com/news/articles/2011-10-04/the-world-s-leading-creative-class-countries [Consultado el 18 de octubre de 2020].

(2010) La clase creativa. La transformación de la cultura del trabajo y el ocio en el siglo XXI. Madrid: Paidós.

(2002) The rise of the creative class. And how it's transforming work, leisure and everyday life. New York: Basic Books. 
García, Jorge (2020) “Teletrabajo en tiempos de coronavirus: ¿Deben pagar las empresas los gastos derivados de trabajar desde casa?". Disponible en: https://www.20minutos.es/ noticia/4236388/0/teletrabajo-coronavirus-deben-pagar-empresas-gastos-derivadostrabajar-casa/ [Consultado el 6 de mayo de 2020].

Gómez, Manuel V. (2020) "España suma 1,1 millones de familias con todos en paro; 600.000 sin ningún ingreso". Disponible en: https://elpais.com/economia/2020-04-28/ espana-suma-11-millones-de-familias-con-todos-en-paro-600000-sin-ningun-ingreso. html [Consultado el 3 de mayo de 2020].

Harvey, David (1990) The condition of postmodernity: an enquiry into the origins of cultural change. Cambridge, MA: Blackwell.

Hernández, Raquel (2020) “Teletrabajo: ¿quién paga los gastos de luz, agua, teléfono e Internet?". Disponible en: https://www.emprendepyme.net/quien-paga-los-gastos-deluz-agua-telefono-e-internet-en-el-teletrabajo.html [Consultado el 19 de octubre 2020].

Hochschild, A. Russell (2012) The outsourced self. Intimate life in market times. NY: Metropolitan Books.

(1997) The time bind. When work becomes home and home becomes work. New York: Metropolitan Books.

Jiménez, Francisco S. (2020). "La cara oculta del teletrabajo: provocará un aumento de la desigualdad salarial y territorial en España”. Disponible en: https://www.eleconomista. es/economia/amp/10537116/La-cara-oculta-del-teletrabajo-provocara-un-aumentode-la-desigualdad-salarial-y-territorial-en-Espana [Consultado el 12 de mayo de 2020]. Kelly, Mark G. E. (2013) “Foucault, subjectivity, and technologies of the self”, en C. Falzon, T. O'Leary, y J. Sawiski (eds.) A Companion to Foucault. Blackwell Publishing Limited.

Lafraya, Conchi (2020) "El teletrabajo se impone en las empresas: respuesta rápida para atajar al coronavirus". Disponible en: https://www.lavanguardia.com/ economia/20200314/474114767539/coronavirus-teletrabajo-espana-covid-19.html [Consultado el 5 de mayo de 2020].

Latour, Bruno (2008) Reensamblar lo social: una introducción a la teoría del actor-red. Buenos Aires: Manantial.

Lloveras, Eli et al. (2009) Innovación en cultura. Una aproximación crítica a la genealogía $y$ usos del concepto. Madrid: Traficantes de sueños.

Magallón, Eduardo (2020a) "El coronavirus destruirá 195 millones de empleos en todo el mundo". Disponible en: https://www.lavanguardia.com/ economia/20200407/48376032939/oit-empleo-paro-covid-19-coronavirus-pandemiacrisis.html [Consultado el 4 de mayo de 2020]. 
(2020b) “Paro España: a economía española destruye 285.600 empleos". Disponible en: https://www.lavanguardia.com/economia/20200428/48780248981/paro-epa-crisiscoronavirus-empleo-covid-19.html [Consultado el 7 de mayo de 2020].

Maqueda, Antonio (2020) "El coronavirus hunde la economía española un 5,2\%, la mayor caída en casi un siglo". Disponible en: https://elpais.com/economia/2020-04-30/ la-economia-espanola-se-hunde-un-52-la-mayor-caida-en-casi-un-siglo.html [Consultado el 30 de abril de 2020].

Mateos, Cristina y Clemente J. Navarro (2014) "La localización de la clase creativa en los municipios españoles. Discusión conceptual-operativa y análisis descriptivo". EMPIRIA. Revista de Metodología de Ciencias Sociales, 29: 123-153.

Medel Vicente, A. (2020) "La tentación del teletrabajo y la pérdida del talento colectivo". Disponible en: https://cincodias.elpais.com/cincodias/2020/04/30/ opinion/1588259464_037539.amp.html [Consultado el 2 de abril de 2020].

Messenger, Jon, Óscar Vargas Llave, Lutz Gschwind, Simon Boehmer, Greet Vermeylen, y Mathijn Wilkens (2017) "Eurofound and the International Labour Office. Working anytime, anywhere: the effects on the world of work", Publications Office of the European Union, Luxembourg, and the International Labour Office. Disponible en: http:// eurofound.link/ef1658

Nippert-Eng, Christena (1996) 'Calendar and keys: the classification of 'home' and 'work"', Sociological Forum, 11(3): 563-582.

Navarro, Vicenç (2008) "España es el país de la UE con peores condiciones de trabajo". Disponible en: https://www.nuevatribuna.es/opinion/vicenc-navarro/espana-es-paisue-peores-condiciones-trabajo/20180223112848148911.html [Consultado el 13 de diciembre de 2020].

OECD (2018) Effective policies, successful schools. The OECD Programme for International Student Assessment (PISA). Volume V. Disponible en: https://doi.org/10.1787/ca768d40en [Consultado el 16 de noviembre de 2020].

(2016) Income inequality remains high in the face of weak recovery. Income Inequality Update. Disponible en: https://doi.org/http://oe.cd/idd [Consultado el 16 de noviembre de 2020].

(2015) In it together: why less inequality benefits all. Disponible en: https://doi. org/10.1787/9789264235120-en [Consultado el 16 de noviembre de 2020].

Olcese, Alejandra (2020) “Teletrabajar por obligación para cuidar a los hijos condena a los padres a discriminación laboral". Disponible en: http://amp.vozpopuli.com/economia-yfinanzas/Teletrabajar-obligacion-condena-discriminacion-laboral_0_1350766384.html [Consultado en 3 de Mayo de 2020]. 
Overell, Stephen (2008) Inwardness: the rise of meaningful work. Vol. 4(2). Provocation series. UK: Work Foundation.

Puentes, Paco (2020) "Coronavirus: UGT y CC OO piden regular el teletrabajo de los empleados públicos con criterios comunes”. Disponible en: https://elpais.com/ economia/2020-04-28/ugt-y-cc-oo-piden-regular-el-teletrabajo-de-los-empleadospublicos-con-criterios-comunes.html [Consultado el 2 de mayo de 2020].

Reygadas, Luis et al. (2012) Empresas de Humanidades. Sectores de Nueva Economía 20+20. Madrid: EOI.

Ross, Andrew (2003) No-collar: the human workplace and its hidden costs. Nueva York: Basic Books.

Rowan, Jaron (2010) Emprendizajes en cultura. Discursos, instituciones y contradicciones de la empresarialidad cultural. Madrid: Traficantes de sueños.

Scace, Richard (2002) Living in the corporate zoo. Life and work in 2010. UK: Capostone Publishing Limited.

Standing, Guy (2013) “Defining the precariat”. Eurozine, 1-7. Disponible en: https:// www.eurozine.com/defining-the-precariat/ [Consultado el 18 de octubre de 2020]

(2011) The Precariat. The new dangerous class. London: Bloomsbury Academic.

Valenzuela-García, Hugo (2021) “Teletrabajo en tiempos de pandemia: bueno para pensar", en A. del Campo Tejedor (ed.) La vida cotidiana en tiempos de la COVID. Una antropología de la pandemia. Madrid: Los libros de la Catarata. Pp. 130-141.

Valenzuela-García, H.; M. Lubbers, JL Molina (2020) Vivo entre Cuatro Paredes. Madrid: Fundación FOESSA.

Valenzuela, Hugo; Cruces, F. y Reygadas, L. (2015) "Mi trabajo es mi vida. La incrustación de los mundos de la vida y del trabajo en empresas españolas”, Revista Española de Investigaciones Sociológicas, 150: 189-208.

Wendell, Joyce (2000) "The evolution of telework in the federal government". Tesis Doctoral, Office of Governmentwide Policy. US General Services Administration. Disponible en: https://rosap.ntl.bts.gov/view/dot/14140 [Consultado el 7 de noviembre de 2020].

World Economic Forum - WEF (2020) “5 hechos impactantes sobre la desigualdad, según el último informe de Oxfam”, Disponible en: https://es.weforum.org/agenda/2020/01/5hechos-impactantes-sobre-la-desigualdad-segun-el-ultimo-informe-de-oxfam/ [Consultado el 12 de noviembre de 2020]. 